\title{
Transient epileptic amnesia: a description of the clinical and neuropsychological features in 10 cases and a review of the literature
}

\author{
Adam Z J Zeman, Simon J Boniface, John R Hodges
}

\begin{abstract}
Objectives-To clarify the clinical and neuropsychological aspects of transient epileptic amnesia (TEA) based on 10 personally studied cases as well as review of 21 previously published cases; and to propose tentative diagnostic criteria for the diagnosis of TEA.
\end{abstract}

Methods-All 10 patients and informants underwent a standardised clinical interview. The radiological and neurophysiological (EEG) data were also reviewed in all cases. The diagnosis of transient epileptic amnesia was made on the basis of the following criteria: (1) there was a history of recurrent witnessed episodes of transient amnesia; (2) cognitive functions other than memory were judged to be intact during typical episodes by a reliable witness; (3) there was evidence for a diagnosis of epilepsy. This evidence was provided by either (a) wake or sleep EEG, or (b) the co-occurrence of other seizure types (if their roughly concurrent onset or close association with episodes of transient amnesia suggested a connection), or (c) a clear cut response to anticonvulsant therapy, or by a combination of these three factors. In addition all patients were administered a comprehensive neuropsychological test battery designed to assess verbal and non-verbal anterograde memory and retrograde memory for famous personalities and personal events. Their results were compared with those of 25 age and IQ matched normal controls.

Results-TEA usually begins in later life, with a mean age of 65 years in this series. Episodes are typically brief, lasting less than one hour, and recurrent, with a mean frequency of three a year. Attacks on waking are characteristic. Repetitive questioning occurs commonly during attacks. The anterograde amnesia during episodes is, however, often incomplete so that patients may later be able to "remember not being able to remember". The extent of the retrograde amnesia during attacks varies from days to years. Most patients experience other seizure types compatible with an origin in the temporal lobes, but transient amnesia is the only manifestation of epilepsy in about one third of patients. Epileptiform abnormalities arising from the temporal lobes are most often detected on interictal sleep EEG. Despite normal performance on tests of anterograde memory, many patients complain of persistent interictal disturbance of autobiographical memory, involving a significant but variable loss of recall for salient personal episodes. The epochs affected may predate the onset of epilepsy by many years.

Conclusions-TEA is an identifiable syndrome and comprises episodic transient amnesia with an epileptic basis, without impairment of other aspects of cognitive function. Future studies should consider the question of whether TEA reflects ictal activity or a postictal state, and the mechanism of the persistent autobiographical amnesia. It is hypothesised that the latter may result in part from impairment of very long term memory consolidation as a result of epileptic activity in mesial temporal structures.

(F Neurol Neurosurg Psychiatry 1998;64:435-443)

Keywords: Transient epileptic amnesia; electroencephalography

It has been recognised for over 100 years that amnesia for episodes of complex and well integrated behaviour can occur in association with temporal lobe epilepsy. ${ }^{12}$ More recent reports have suggested that transient amnesia is sometimes the only manifestation of a temporal lobe seizure, and indeed that it may be the only seizure type to occur in some patients. ${ }^{3-6}$ Seizures causing prominent amnesia are easily mistaken for episodes of transient global amnesia $(\mathrm{TGA})^{7}$ or of psychogenic amnesia. ${ }^{8}$ Various terms has been used to describe these attacks including pure amnestic seizures, ${ }^{9}$ ictal amnesia,${ }^{10}$ epileptic amnesia, ${ }^{11}$ epileptic amnesic attacks, ${ }^{412}$ epileptic transient amnesia, ${ }^{13}$ and transient epileptic amnesia or TEA. ${ }^{6}{ }^{14}$ We have adopted the last of these terms to highlight the similarity of this syndrome to, but also its distinction from, TGA.Our aims were to clarify the clinical and neuropsychological features of this disorder in the light of 10 cases of TEA studied prospectively, and to compare these with the features suggested by 15 previously published reports of 21 cases. The largest previous series describes four cases. ${ }^{6}$ We focus on the following questions: (1) Is transient amnesia a distinctive presentation of temporal lobe epilepsy? If so, what are its characteristic features? (2) What is the pathophysiology of TEA, and in particular is it an ictal or postictal phenomenon? (3) Is TEA associated, as Kapur has suggested, ${ }^{6}$ with a persistent interictal 
disturbance of retrograde memory? If so, what mechanism is responsible?

\section{Methods}

PATIENTS AND DIAGNOSTIC CRITERIA

Patients had initially been referred to the Memory and Cognitive Disorders Clinic at Addenbrooke's Hospital, Cambridge (four) or seen in general neurology clinics in East Anglia by the authors (four) or their colleagues (two). The diagnosis of transient epileptic amnesia was made on the basis of the following criteria: (1) there was a history of recurrent witnessed episodes of transient amnesia; (2) cognitive functions other than memory were judged to be intact during typical episodes by a reliable witness; (3) there was evidence for a diagnosis of epilepsy. This evidence was provided by either (a) wake or sleep EEG, or $(b)$ the co-occurrence of other seizure types (if their roughly concurrent onset and/or close association with episodes of transient amnesia suggested a connection), or (c) a clear cut response to anticonvulsant therapy, or by a combination of these three factors.

STUDY PROTOCOL

History and examination

We reviewed the history of attacks in detail with the patient and with a witness (who was a spouse in every case) independently, and enquired whether any other memory problems had been noticed by either patient or spouse, following the methods described by Hodges. ${ }^{15}$ Other information regarding handedness, education and work history, risk factors for epilepsy (for example, birth history, febrile convulsions, head injury, CNS infections, alcohol use, family history), other medical history, psychiatric history, and drug history was collected using a proforma designed for the study. The patients underwent a standard neurological examination.

\section{Investigations}

All EEGs (16 channel digital and/or analogue with a 10/20 montage) were assessed by one of us (SB). If a sleep EEG (sleep deprived or drug induced) had not already been performed, one was arranged. Sleep deprived EEGs were performed after three to four hours of sleep deprivation on the preceding night. Drug induced sleep EEGs were performed after the administration of $300 \mathrm{mg}$ amylobarbitone by mouth. Interictal EEG features were classified as follows: ${ }^{16}(1)$ epileptiform, with reproducible examples $(>2)$ of unequivocal focal epileptiform complexes; (2) non-reproducible, with two or less unequivocal epileptiform focal abnormalities of comparable waveform in 30 minutes; (3) polyrhythmic, with brief polyrhythmic abnormalities of no diagnostic relevance; (4) normal, with none of the above abnormalities. Normal small sharp spikes and regional slow wave rhythms or complexes attributable to the effects of aging or vascular lesions were all excluded. Neuroimaging was reviewed.
Neuropsychology

A battery of tests designed to assess verbal and non-verbal anterograde recall and recognition memory, and retrograde memory for public and personal events, was administered to each patient. These were the national adult reading test, ${ }^{17}$ immediate and delayed story recall from the Wechsler memory scale revised, ${ }^{18}$ reproduction and delayed recall of the ReyOsterrieth complex figure, ${ }^{19}$ the recognition memory test for words and faces, ${ }^{20}$ famous faces and famous names tests, ${ }^{21}$ and the autobiographical memory interview. ${ }^{22}$ the patients' results were compared with those from 25 normal controls from the MRC Applied Psychology Unit's panel matched for age, years of education, and NART score using one tailed tests (see below). To examine the performance of individual patients, we also identified instances in which the patients' scores fell below 2 SD of the controls' mean on any test.

\section{Results}

\section{DEMOGRAPHY}

Table 1 shows that nine of our 10 patients were men. Their ages ranged from 49-73 with a mean of 65 . The aetiology of their epilepsy was uncertain, but preceding vascular events were common: three patients (cases 3,5, and 7) had a history of myocardial infarction, one patient (case 6) had recently undergone aortic valve replacement, and another (case 9) coronary artery bypass grafting. Two patients (cases 1 and 8) reported significant head injuries with loss of consciousness in early adulthood: the post-traumatic amnesia had been negligible in the first case and had lasted two hours in the second.

\section{CRITERIA FOR DIAGNOSIS}

Table 1 shows that four patients had unequivocal reproducible abnormalities referable to the temporal lobes on wake or sleep EEG (see below). Of the remaining six patients, five had other seizure types which lent support to the diagnosis of epilepsy (see below), and in the remaining case anticonvulsant treatment abolished the amnesic episodes. In six of the 10 patients more than one factor supported the diagnosis of epilepsy.

CHARACTERISTICS OF THE AMNESIC EPISODES Table 1 shows that at the time of the diagnosis of TEA, the history of amnesic episodes ranged in duration from four months to 14 years, with a mean of three years. The number of episodes ranged from three to 20 with a mean of nine. In six patients all episodes had lasted for one hour or less, in two patients some but not all attacks had lasted for an hour or less, whereas in the remaining two patients attacks had always lasted hours, and sometimes days. Anterograde and retrograde memory were both disturbed in typical episodes, but five patients had partial recall for at least some attacks, suggesting that the anterograde amnesia was incomplete. Nine of the 10 patients had questioned their companions repetitively during episodes. The retrograde amnesia during attacks was sometimes brief, but all patients had experienced 
Table 1 Current series: clinical, EEG, and neuropsychological features

\begin{tabular}{|c|c|c|c|c|c|c|c|c|c|c|c|c|}
\hline Case & Age & Sex & $\begin{array}{l}\text { History } \\
\text { (duration) }\end{array}$ & Attacks & $\begin{array}{l}\text { Attack } \\
\text { (duration) }\end{array}$ & $\begin{array}{l}\text { Repetitive } \\
\text { questioning }\end{array}$ & $\begin{array}{l}\text { Sleep } \\
\text { related }\end{array}$ & EEG findings & Rx response & $\begin{array}{l}\text { Other } \\
\text { epilepsy }\end{array}$ & $\begin{array}{l}\text { TEA } \\
\text { aura }\end{array}$ & $\begin{array}{l}\text { Focal retrograde } \\
\text { amnesia }\end{array}$ \\
\hline 1 & 63 & $M$ & $3 y$ & 20 & $1 \mathrm{~h}$ & + & + & - & $+\mathrm{CBZ}$ & sps & $+1-$ & + \\
\hline 2 & 49 & M & 4 months & 12 & $<1 \mathrm{~h}$ & + & + & +Bilateral & $+\mathrm{CBZ}$ & sps & $+1-$ & + \\
\hline 3 & 68 & M & 8 months & 5 & h-days & + & + & +Bilateral & + SVP & $\mathrm{sps}, \mathrm{cps}$ & - & + \\
\hline 4 & 66 & $\mathrm{~F}$ & 14 & 5 & $<1 h \geqslant 1 h$ & + & + & $+\mathrm{L}$ & E CBZ & - & - & - \\
\hline 5 & 79 & $M$ & 15 months & 3 & h-days & + & + & +Bilateral & E CBZ & - & - & + \\
\hline 6 & 70 & M & $2 \mathrm{y}$ & 13 & $<1 \mathrm{~h}$ & + & + & Polyr & no $R x$ & $\mathrm{sps}$ & $+1-$ & - \\
\hline 7 & 73 & $M$ & 6 months & 5 & $1-2 \mathrm{~h}$ & - & + & Polyr & $+\mathrm{P}$ & - & - & - \\
\hline 8 & 60 & $M$ & 6 months & 3 & $<1 h \geqslant 1 h$ & + & + & - & + SVP & tcl & - & + \\
\hline 9 & 69 & $M$ & 4 months & 3 & $<1 \mathrm{~h}$ & + & + & - & $+\mathrm{CBZ}$ & cps & $+1-$ & + \\
\hline 10 & 56 & $M$ & 9 months & 20 & $<1 \mathrm{~h}$ & + & + & - & $+\mathrm{CBZ}$ & $\mathrm{cps}, \mathrm{tcl}$ & - & + \\
\hline
\end{tabular}

Polyr $=$ polyrhythmic abnormalities present $\mathrm{Rx}$ response $=$ treatment response $(+=$ abolition or substantial reduction of episodes, $\mathrm{E}=$ equivocal reduction, $\mathrm{CBZ}=$ carbamazepine; $\mathrm{P}=$ phenytoin, $\mathrm{SVP}=$ sodium valproate); $\mathrm{sps}=$ simple partial seizures; $\mathrm{cps}=$ complex partial seizures; tcl $=$ tonic-clonic seizures; TEA aura = occurrence of co-occurring seizure type as prodrome of amesic episode $(+=$ co-occurring seizure type always precedes TEA, $+/-=$ co-occurring seizure type sometimes precedes TEA, $-=$ no co-occurring seizure type).

attacks in which it extended over several months. It is noteworthy that in six of the 10 the retrograde amnesia sometimes extended over many years. In every case at least one episode had occurred on waking. Nine patients were treated with anticonvulsant drugs and one declined treatment; in seven there was clear cut benefit, with abolition of overt attacks in six and pronounced reduction of frequency in the seventh. In the remaining two patients the effects of treatment are uncertain, in one patient because of a short period of follow up, in the other because attacks had occurred only at long intervals before the initiation of treatment.

\section{OTHER SEIZURE TYPES}

Table 1 shows that seven of the 10 patients reported other types of epileptic phenomena. These comprised olfactory hallucinations in two patients (cases 1 and 3), frequent episodes of déjà vu in one patient (case 6), episodes of vertigo in one patient (case 2), complex partial seizures in three (cases 3, 9, and 10), and tonic-clonic seizures in two patients (cases 8 and 10). In four patients (cases 1, 2, 6, and 9) these phenomena sometimes preceded amnesic episodes. In all cases the other seizure types had first occurred at around the same time as the amnesic episodes with the exception of patient 6 who recalled a brief flurry of episodes of déjà vu occurring about 45 years ago. In three patients (cases 4,5 , and 7 ) there was no history from either patient or spouse to suggest the occurrence of any epileptic phenomena apart from the amnesic episodes themselves.

\section{RETROGRADE AMNESIA AND OTHER MEMORY} COMPLAINTS

Table 1 shows that seven of the 10 patients complained spontaneously of an unusual and persistent impairment of remote memory. In every case this included an inability to recall some salient episodes from their personal lives. This was often first noted when the patients encountered photographs of episodes from recent holidays and realised that they had no recollection of them. In all cases, the patients and their spouses thought that this impairment was "patchy", with preservation of recall for some, but loss of recall for other, episodes. The impairment was more severe for episodes from recent years than for the distant past, but in five of the seven cases the impairment affected recall for episodes which predated the clinical onset of TEA. In these five patients, the retrograde memory disorder extended from a minimum of 18 months to a maximum of about 30 years (case 3). Six patients gave a history suggestive of topographical amnesia, with failure to recognise familiar landmarks and to recall familiar routes. Three complained of difficulty in recalling the names of longstanding friends and acquaintances, and two complained that they had lost their grasp of techniques which they had used professionally for many years. Patients were asked to assess their day to day anterograde memory as well as their recall for more remote events: only one of the seven patients who complained of an impairment of retrograde memory (case 10) thought that he had a comparable disturbance of day to day memory.

\section{PSYCHIATRIC BACKGROUND}

Two patients gave a history of mood disorder. Patient 9 experienced lowering of his mood after retirement and was being treated with sertraline at the onset of his episodes of transient amnesia; patient 10 had a long history of intermittent depression, preceding the onset of his episodic amnesia. He had received treatment with paroxetine for an exacerbation of depression some months after the onset of amnesic episodes. A history of possible past psychiatric disorder was obtained in two other patients: patient 1 had been seen by a neurologist on two occasions, seven and 24 years before the onset of his current illness, with symptoms which were attributed to stress. Patient 6 had a history of excessive alcohol but his episodes of amnesia had not occurred in the context of alcohol misuse.

\section{NEUROPHYSIOLOGY}

Table 1 shows that all patients had sleep EEGs; in eight of the 10 cases these were preceded by wake records. Amylobarbitone was used to induce sleep in five patients, and five patients were sleep deprived. Four patients had clear cut epileptiform EEG abnormalities as defined above. In one of these (case 4) the wake EEG was normal, in two (cases 2 and 3 ) the wake EEGs showed non-reproducible epileptifom abnormalities. The remaining patient (case 5) did not have a wake EEG: epileptiform discharges were detected in both the wake and sleep portions of his sleep deprived EEG. 
Table 2 Neuropsychological test results

\begin{tabular}{|c|c|c|}
\hline & $\begin{array}{l}\text { TEA } \\
\text { mean (SD) }\end{array}$ & $\begin{array}{l}\text { Controls } \\
\text { mean }(S D)\end{array}$ \\
\hline \multicolumn{3}{|c|}{ Anterograde memory tests (maximum score in parenthesis): } \\
\hline Age & $65(9)$ & $70(8)$ \\
\hline Education $(\mathrm{y})$ & $12(2)$ & $11(2)$ \\
\hline NART & $115(6)$ & $119(7)$ \\
\hline \multicolumn{3}{|l|}{ Story recall WMS: } \\
\hline Immediate (21) & $13(4)$ & $12(4)$ \\
\hline Delayed (21) & $10(3)$ & $9(3)$ \\
\hline \multicolumn{3}{|l|}{ Rey-Ostereith figure: } \\
\hline Copy (36) & $35(1)$ & $34(3)$ \\
\hline Delayed recall (36) & $20(4)$ & $15(8)$ \\
\hline \multicolumn{3}{|l|}{ Recognition memory test: } \\
\hline Words $(50)$ & $46(3)$ & $47(3)$ \\
\hline Faces $(50)$ & $43(4)$ & $44(4)$ \\
\hline \multicolumn{3}{|c|}{ Retrograde memory tests (maximum scores in parenthesis): } \\
\hline \multicolumn{3}{|l|}{ Famous faces test } \\
\hline Recognition (50) & $47(2)$ & $43(7)$ \\
\hline Identification (50) & $38(5)$ & $39(9)$ \\
\hline Naming (50) & $26(10)$ & $31(4)$ \\
\hline \multicolumn{3}{|l|}{ Famous names test } \\
\hline Recognition (50) & $49(1)$ & $50(1)$ \\
\hline Identification (50) & $46(2)$ & $49(1)$ \\
\hline \multicolumn{3}{|c|}{ Autobiographical memory interview: } \\
\hline \multicolumn{3}{|c|}{ Personal semantic: } \\
\hline Childhood (21) & $19(2)$ & $20(2)$ \\
\hline Early adulthood (21) & $18(2)$ & $20(2)$ \\
\hline Late adulthood (21) & $20(2)$ & $20(1)$ \\
\hline \multicolumn{3}{|l|}{ Personal incident: } \\
\hline Childhood (9) & $8(2)$ & $7(2)$ \\
\hline Early adulthood (9) & $7(2)$ & $8(2)$ \\
\hline Late adulthood (9) & 7 (3) & $7(2)$ \\
\hline
\end{tabular}

Patients 3 and 4 had drug induced sleep EEGs; patients 2 and 5 were sleep deprived. In all cases the discharges were referable to the anterior or mid-temporal lobe. They were bilateral and independent in three of the four patients (cases 2, 3, and 5). Two of the six remaining records (cases 6 and 7) showed sparse focal polyrhythmic abnormalities on sleep EEG.

NEUROIMAGING

All patients had CT except for patient 1 . These were within normal limits. Four patients had MRI; these were normal in patients 1 and 2; in patient 5 there was evidence of focal infarction in the posterior corpus callosum and in patient 10 there was focal atrophy of the anterior and mid-hippocampus on the right. HMPAOSPECT was performed in patients 1 and 3; both showed a minor degree of frontal lobe hypoperfusion.

NEUROPSYCHOLOGY

Table 2 shows that although there were no significant differences between the group data for patients and controls on any of the demographic or neuropsychological variables, analysis of individual patient's scores disclosed that seven had impaired performance on at least one test (as judged by obtaining a score more than 2 SD below the control group mean). Interestingly, all but one of these tests examined retrograde memory: the famous faces test (two patients), the famous names test (four patients), the autobiographical memory interview (three patients), and the recognition memory test (one patient). In total, five patients showed impairment of one or more tests of remote memory but in most cases, their scores were only just below the 2 SD cut off. Only one score (for the autobiographical memory interview in patient 2 , described below) fell more than 3 SD below the control mean.
The cases are briefly summarised below:

Case 1

A 63 year old engineer had experienced about 20 episodes of transient amnesia lasting for around one hour each over the past three years. Most had occurred on waking. He would characteristically say "I'm not sure where I am" at the onset; his conversation would then disclose a retrograde amnesia extending back for about 10 years. He has no recall for events during the attacks. In other respects, he converses and behaves normally during attacks. Over the year before presenting to us he had complained to his wife of a "strange smell or taste" which he noticed at the onset of attacks. He had been knocked out by a fly press in 1966. MRI and wake and sleep EEG were normal. Treatment with carbamazepine abolished the attacks.

Case 2

A 49 year old businessman presented with a four month history of brief episodes of vertigo accompanied by "ringing in the ears", which usually woke him from sleep and which was often followed by a period of amnesia lasting for less than one hour. Amnesia on waking sometimes occurred without the prodrome of vertigo. The amnesic episodes involved retrograde amnesia for up to 30 years accompanied by incomplete anterograde amnesia. Apart from repetitive questioning to his wife, behaviour during attacks was normal. During this period he has developed a patchy persistent amnesia for recent events. Brain MRI was normal but sleep and wake EEG showed independent unequivocal bitemporal epileptiform abnormalities. Treatment with carbamazepine has abolished the amnesic episodes.

Case 3

A 68 year old retired engineer gave an eight month history of episodes of amnesia which usually occurred on waking, and involved extensive retrograde amnesia with incomplete anterograde amnesia for the episodes themselves. Apart from occasional repetitive questioning his behaviour was normal during the initial attacks. He sometimes complained of an odd taste or smell. Seven months after the first attack he had an episode of amnesia during which he was clearly confused and unable to dress himself; after this, his wife described episodes in which he became inaccessible for a few minutes, with no subsequent recall of events during the episodes. During this period it became clear that he had developed an extensive patchy retrograde amnesia for events of the past 30 years. He had a history of myocardial infarctions seven and nine years ago. Brain CT was normal and SPECT showed minor reduction in uptake frontally. Wake EEG showed sharpened theta activity in both temporal lobes; sleep deprived EEG showed independent bitemporal unequivocal epileptiform abnormalities. Treatment with sodium valproate abolished the episodes of overt amnesia. 
Table 3 Previously reported cases: clinical, EEG, and neuropsychological features

\begin{tabular}{|c|c|c|c|c|c|c|c|c|c|c|c|c|c|}
\hline Reference & Age & $\operatorname{Sex}$ & $\begin{array}{l}\text { History } \\
\text { (duration) }\end{array}$ & Attacks (n) & $\begin{array}{l}\text { Attack } \\
\text { (duration) }\end{array}$ & $\begin{array}{l}\text { Repetitive } \\
\text { questioning }\end{array}$ & $\begin{array}{l}\text { Sleep } \\
\text { related }\end{array}$ & $\begin{array}{l}E E G \\
\text { findings }\end{array}$ & $\begin{array}{l}R x \\
\text { response }\end{array}$ & $\begin{array}{l}\text { Other } \\
\text { epilepsy }\end{array}$ & $\begin{array}{l}\text { TEA } \\
\text { aura }\end{array}$ & $\begin{array}{l}\text { Focal } \\
\text { retrograde } \\
\text { amnesia }\end{array}$ & $\begin{array}{l}\text { Memory } \\
\text { tests }\end{array}$ \\
\hline $\mathrm{Lou}^{50}$ & 61 & $M$ & $?$ & 9 & $15 \mathrm{~min} \geqslant \mathrm{~h}$ & + & + & $+\mathrm{R}$ & $+\mathrm{OXZ}$ & - & - & - & Ant \\
\hline Shuping $^{24}$ & 60 & $M$ & ? & 3 & $<1 \mathrm{~h}$ & ? & ? & - & - & tcl & - & - & ND \\
\hline Deisenhammer $^{23}$ & 11 & $\mathrm{~F}$ & 1 month & 4 & $<1 \mathrm{~h}$ & + & + & $+\mathrm{R}$ & $+\mathrm{CBZ}$ & - & - & - & ND \\
\hline Dugan et al ${ }^{\beta}$ & 82 & M & 2 months & 3 & $3-4 \mathrm{~h}$ & + & $?$ & +Bilateral & $+\mathrm{P}$ & - & - & - & ND \\
\hline$\underset{\mathrm{i}}{\text { Pritchard } e t a l^{4}:}$ & 65 & $M$ & $4 \mathrm{y}$ & 10 & $<15 \min$ & - & ? & +Bilateral & $+\mathrm{P}$ & - & - & ? & ND \\
\hline $\mathrm{ii}$ & 64 & $M$ & 6 months & 3 & $1-24 \mathrm{~h}$ & - & ? & +Bilateral & $+\mathrm{CBZ}$ & - & - & ? & ND \\
\hline Meador $e t a l^{5}$ & 47 & $\mathrm{~F}$ & 10 months & 2 & $<1 \mathrm{~h}$ & - & - & +Bilateral & $+\mathrm{P} /$ surg & cps & - & & Normal \\
\hline $\begin{array}{l}\text { Galassi et } a l^{12} \\
\text { Gallassi et } a b^{66}\end{array}$ & 67 & $M$ & $2 \mathrm{y}$ & 25 & $<1 \mathrm{~h}$ & + & + & ThetaR & E P & $\mathrm{sps} / \mathrm{cps}$ & + & Imp mem & Verb \\
\hline i & 70 & $\mathrm{~F}$ & $3 y$ & 2-3/weeks & $<1 \mathrm{~h}$ & + & ? & $+\mathrm{R}$ & $+\mathrm{CBZ}$ & cps & + & Imp mem & Vis/verb \\
\hline ii & 66 & M & $2 \mathrm{y}$ & $1 / \mathrm{m}$ & $<1 \mathrm{~h}$ & + & $?$ & ThetaL & $+\mathrm{CBZ}$ & cps & + & Imp mem & Verb \\
\hline Miller et $a \bar{l}^{\overline{0}}$ & & & & & & & & & & & & & \\
\hline $\mathrm{i}$ & 62 & M & 14 months & 8 & $<30$ mins & + & + & +Bilateral & $+\mathrm{P}$ & - & - & - & ND \\
\hline ii & 22 & ? & Weeks & Several & $<1 \mathrm{~h}$ & ? & ? & $+\mathrm{L}$ & + ? & cps & $+/-$ & ? & ND \\
\hline Stracciari et $a l^{13}$ & 70 & $\mathrm{~F}$ & 8 months & 8 & $10 \mathrm{~min}-7 \mathrm{~h}$ & + & - & $+\mathrm{L}$ & $+\mathrm{CBZ}$ & cps & $+/-$ & Imp mem & Vis/verb \\
\hline $\begin{array}{l}\text { Kapur }^{37} \\
\text { Kapur }^{6} \text { : }\end{array}$ & 74 & M & $5 \mathrm{y}$ & 20 & $30 \mathrm{~min} \geqslant \mathrm{~h}$ & $?$ & + & +Bilateral & $?$ & cps & $+/-$ & + & Retro \\
\hline i & 63 & $\mathrm{~F}$ & $3 y$ & 35 & Mins $\geqslant h$ & - & ? & ThetaL & + SVP & cps & $+/-$ & Imp mem & Vis/retro \\
\hline ii & 67 & $\mathrm{~F}$ & 4 months & 6 & $30 \min -1 \mathrm{~h}$ & - & $?$ & ThetaL & $+\mathrm{P}$ & - & - & - & Normal \\
\hline iii & 28 & M & ? & 20 & 1-2 day & + & + & +Bilateral & $+\mathrm{CBZ} / \mathrm{P}$ & $\mathrm{cps}$ & $+/-$ & ? & Vis/verb \\
\hline iv & 61 & $\mathrm{~F}$ & ? & 2 & Min & ? & + & $+\mathrm{L}$ & $+\mathrm{CBZ}$ & $\mathrm{cps}$ & $+/-$ & Imp mem & ? \\
\hline $\mathrm{v}$ & 60 & $M$ & $3 \mathrm{y}$ & Many & $10-15 \mathrm{~min}$ & + & ? & +Bilateral & $+\mathrm{CBZ}$ & sps, cps & + & ? & Verb \\
\hline vi & 54 & $M$ & 21 months & 8 & $30 \mathrm{~min}-1 \mathrm{~h}$ & + & ? & +Bilateral & $+\mathrm{P}$ & cps & $+/-$ & + & Ant \\
\hline Vuilleumier $e t a b^{4}$ & 41 & $\mathrm{~F}$ & $\geqslant 20 y$ & Many & Hours & - & + & +Bilateral & $+\mathrm{CBZ}$ & sps & + & - & Normal \\
\hline
\end{tabular}

$\mathrm{Rx}$ response $=$ treatment response $(+=$ abolition or substantial reduction of episodes, $\mathrm{E}=$ equivocal reduction, $\mathrm{CBZ}=$ carbamazepine, $\mathrm{P}=$ phenytoin, $\mathrm{SVP}=$ sodium valproate, $\mathrm{OXZ}=$ oxazepam, surg $=$ surgery $)$; other epilepsy $=$ other co-occurring seizure types, $($ sps $=$ simple partial seizures, $\mathrm{cps}=$ complex partial seizures, tcl $=$ tonic-clonic seizures); TEA aura $=$ occurrence of co-occurring seizure type as prodrome of amesic episode, $(+=$ co-occurring seizure type always precedes TEA, $+/-$ = co-occurring seizure type sometimes precedes TEA, $-=$ no co-occurring seizure type); Imp mem $=$ complaint of impaired memory not further specified; vis/verb $=$ deficits on tests of anterograde visual/verbal memory; ant = anterograde memory impairment not further specified; retro = deficits on tests of retrograde memory.

Case 4

A 67 year old housewife experienced four episodes of transient amnesia, lasting from a few minutes to several hours, over the course of 15 years. Anterograde amnesia was incomplete in the first two episodes but the third and fourth were clinically indistinguishable from transient global amnesia. Behaviour was normal during the episodes apart from repetitive questioning. Brain CT and wake EEG were normal, but a sleep record showed unequivocal left temporal epileptiform abnormalities. On treatment with carbamazepine she had had one further episode lasting 20 minutes.

Case 5

A 79 year old retired manager experienced several episodes of amnesia lasting hours or days. At least one episode occurred on wakening. He asked questions repetitively during the episodes. Over the same period he developed a patchy amnesia for recent events. Two and a half years before presentation he had had a myocardial infarct. Brain MRI disclosed an area of infarction in the posterior corpus callosum. EEG showed independent bitemporal unequivocal independent epileptiform abnormalities. Follow up after starting treatment with carbamazepine has been too brief to judge the response.

Case 6

A 70 year old retired surveyor had experienced unusually frequent episodes of déjà vu in his mid-20s. He presented to us with a two year history of numerous episodes of dense anterograde amnesia lasting minutes, with some retrograde amnesia, sometimes occurring on waking and often preceded by a sense of déjà vu. He questioned his wife repetitively during these episodes, but could perform complex tasks-for example, playing cards. $\mathrm{He}$ was drinking up to 10 units of alcohol a day at the onset of these episodes and required an aortic valve replacement during this period. An EEG showed right temporal polyrhythmic abnormalities; brain CT was normal. He declined treatment.

\section{Case 7}

A 73 year old retired electrician presented with a history of five attacks of amnesia lasting one to two hours over the preceding six months. He typically complained of feeling odd at the onset, and sometimes of a strange feeling over the left side of his face. He would then ask "What are we doing here?", and question his wife repetitively. His questions sometimes betrayed amnesia for recent events. One attack occurred on waking in the early hours. Brain CT was normal; EEG showed right temporal polyrhythmic abnormalities. Treatment with phenytoin abolished the attacks.

\section{Case 8}

A 60 year old printer presented after three episodes of amnesia in the last six months. The first occurred on waking and involved repetitive questioning, lasting for at least one hour. Shortly after this he had a tonic-clonic seizure in sleep. The third amnesic episode culminated in a series of brief generalised convulsions. $\mathrm{He}$ developed a patchy retrograde amnesia for recent events, familiar faces, and places. He had a history of head injury with loss of consciousness in a motorbike accident at the age of 18. Brain CT and wake and sleep EEGs were normal. There have been no more attacks since treatment with sodium valproate was started.

\section{Case 9}

A 69 year old retired civil engineer had experienced three episodes of amnesia in four 
months. Two of these occurred on waking and involved anterograde amnesia, with repetitive questioning, and retrograde amnesia for recent events. Several subsequent episodes of amnesia followed brief spells of loss of consciousness which were sometimes preceded by lip smacking and sometimes associated with scanty convulsive movements. Over the same period he developed a patchy amnesia for events of the past three years. He had had triple coronary artery bypass surgery two years before. Shortly before the onset of these episodes sertraline had been prescribed for depression. Brain CT and wake and sleep EEGs were normal. There have been no further attacks since starting treatment with carbamazepine.

Case 10

A 56 year old lecturer reported numerous episodes of anterograde amnesia, accompanied by retrograde amnesia for recent events, lasting for less than one hour, over a nine month period. These commonly occurred on waking from naps. On other occasions, however, his wife saw him "drift off into a trance and make choking noises for a second or two", after which he would be amnesic. He went on to have three witnessed tonic-clonic convulsions, shortly after starting paroxetine for depression. He complained of poor memory for day to day events and for familiar places, and of abnormal forgetting over time. Brain MRI showed focal atrophy of the right hippocampus. Sleep EEG was normal. Since starting treatment with carbamazepine there have been no further episodes of amnesia or overt seizures.

\section{Discussion}

VALIDATION OF TEA AS A DISTINCT NEUROLOGICAL ENTITY

Table 3 shows several previous reports that have suggested that episodes of transient amnesia, often closely resembling the syndrome of transient global amnesia, can have an epileptic basis, but this fact has not received wide acceptance. Our 10 cases provide further evidence for the existence of TEA which we argue is a distinctive manifestation of temporal lobe epilepsy. The evidence is most persuasive in those patients with support from all three criteria adopted in this study: epileptiform discharges on EEG, concurrent onset of other seizure types, and a response to anticonvulsant therapy. Of these three criteria, the first two are the strongest. Two of the patients in this study (cases 2 and 3) satisfy all three criteria; four others (cases 2, 8, 9, and 10) satisfy two; cases $4,5,6$, and 7 satisfy one criterion each. We have included the third group, in which the diagnosis is least certain, on the hypothesis that the clinical features of their attacks are identical to those in the first two groups and reflect, therefore, a common mechanism of transient amnesia.

CLINICAL CHARACTERISTICS OF TEA

Table 3 summarises these previously reported cases. The reports have generally applied similar criteria for diagnosis to those we have used, with some exceptions: in four of the 21 patients, ${ }^{11-13}$ amnesic episodes always followed complex partial seizures; some reports do not mention whether a description from a witness was available. The onset of attacks is commonly in middle or old age. Only one case in the literature, ${ }^{23}$ and none in the present series had amnesic episodes below the age of 40 . The aetiology of the epilepsy is usually obscure, with negative results from neuroimaging, although two previous cases were associated with tumour, ${ }^{24} 25$ and right hippocampal atrophy was noted in one of our patients (case 10). A history of cardiac disease was common among our patients, suggesting that cardiac related hypoxic damage to mesial temporal lobe structures may be mediating their epilepsy. The attacks themselves have several distinctive features:

(1) they tend to be more numerous than episodes of TGA. In our series the mean number of attacks was nine, at a rate of three attacks a year. This compares with a recurrence rate of about 3\% a year for episodes of TGA. ${ }^{7}$

(2) Episodes of TEA are usually relatively brief: eight of 10 of our patients and 17 of 21 of the previously reported cases had at least some attacks lasting less than one hour. This compares with a mean duration of four to six hours for attacks of TGA. ${ }^{7}$

(3) The occurrence of attacks on waking is characteristic. Every patient in our series reported at least one such attack; they were a typical feature in six of 10. Likewise attacks on waking were noted in eight of 10 previously reported cases for which this information is available. By contrast, episodes of TGA sometimes occur on rising in the morning, but probably no more often than would be expected by chance. ${ }^{26}$ By contrast with Kapur's finding, ${ }^{6}$ that repetitive questioning is unusual in TEA, all but one of our patients had questioned a companion repetitively during at least one attack. One feature which may distinguish TEA from TGA is, however, the ability to recall some details about the amnesic episode: half of our patients had some recall for their attacks. In particular, they were "able to remember not being able to remember" recent events during attacks, indicating that their anterograde amnesia during the attack was sometimes incomplete. Whereas this feature may distinguish TEA from TGA, a careful standardised comparison between patients with the two conditions is required to reach a definite conclusion on this point. Retrograde amnesia of variable duration is undoubtedly a common feature during attacks of TEA. It was noted in all our cases, and in all those cases in the literature in which the issue is discussed, with the exception of the cases described by Palmini et al. ${ }^{9}$ whereas their findings show that inconspicuous or unnoticed anterograde amnesia may be the sole manifestation of temporal lobe epilepsy, the claim that all "amnestic seizures" are of this kind is not compelling: patients included in this study were highly selected, and all had a pre-existing diagnosis of intractable temporal lobe epilepsy. We return to this issue below. Isolated transient amnesia may, on occasions, be the sole manifestation of 
epilepsy. In three of our 10 patients, and in seven of 21 cases in the literature $(32 \%$ overall), episodic amnesia was the only manifestation of epilepsy. We disagree therefore with Palmini et al who concluded that pure amnestic seizures "never represent the only type of seizures" in patients with temporal lobe epilepsy. Their study considered only patients with pre-existing temporal lobe epilepsy. Our findings suggest that temporal lobe epilepsy is an important diagnosis to consider in patients with brief recurrent episodes of amnesia, especially if they occur on waking. This is consistent with the results of Hodges ${ }^{7}$ who reported that eight of 114 patients satisfying strict criteria for TGA subsequently developed epilepsy; six of these had complex partial seizures. In this study patients with more than one episode of "TGA" and/or episodes of less than hour were at an increased risk of subsequent epilepsy by comparison with patients with single protracted episodes. A recent study by Melo et $a l^{27}$ disputed this view on the grounds that only one of their five patients with brief recurrent episodes diagnosed as TGA proved to have epilepsy. We would not claim that all brief recurrent amnesic episodes have an epileptic basis. It could be relevant that Melo et al did not report the results of sleep EEGs.

\section{PATHOPHYSIOLOGY OF TEA}

Interictal temporal lobe epileptiform abnormalities are sometimes non-localising because of either neurophysiological propagation or volume conduction. In combination with the clinical features of associated seizures, however, these features imply that TEA is a pathophysiological phenomenon of the temporal lobe.

\section{Does TEA result from mesial temporal} dysfunction?

The critical role of the mesial temporal lobes (hippocampus subiculum, parahippocampal gyrus, and entorhinal cortex) in the acquisition of new memories and the retrieval of recent ones is well established. ${ }^{28}{ }^{29}$ It is plausible, therefore, that dysfunction of these structures is responsible for TEA. The preponderance of anterior and mid-temporal abnormalities in our series is consistent with a mesial temporal origin, but these may have been propagated rather than volume conducted. Surface EEGs do not permit precise localisation of the underlying electrical focus, as three dimensional localisation of the epileptogenic region from digital surface EEG is model dependent and independent bitemporal interictal abnormalities do not necessarily imply bilateral pathology. Information from a few in depth studies supports the view that epileptic amnesia results from current or recent paroxysmal activity in the mesial temporal lobes. ${ }^{90-32}$

IS TEA AN ICTAL OR A POST-ICTAL STATE?

Several reports bear on the question of whether TEA is likely to be an ictal or a postictal state. Palmini et al ${ }^{9}$ describe a brief episode of bilateral mesial temporal epileptiform activity associated with disruption of anterograde memory. The patient successfully conducted a telephone conversation during this episode for which she later had no recall. She had been unaware at the time that anything was wrong. This case shows that a period of pure anterograde amnesia can be the manifestation of a mesial temporal seizure. On the other hand, it has also been shown that recently acquired memories are vulnerable to transient temporal lobe seizures. Bridgman et $a l^{30}$ reported that a subclinical unilateral hippocampal seizure, without spread to the temporal neocortex, disrupted recall of a previously learned word list. Similarly, Halgren et $a \beta^{33}$ showed that brief bilateral stimulation of mesial temporal structures at either the time of memory acquisition, or the time of memory retrieval, could disrupt performance without any other effect on behaviour. Taken together, these findings suggest that ictal activity in mesial temporal structures is capable of disrupting both anterograde and retrograde memory, and that this disruption may go unnoticed by the subject. Can longer periods of amnesia occur as an ictal phenomenon or are these always postictal? Lee $e t a l^{2}$ describe the remarkable case of a previously well 38 year old woman in whom a 12 day period of continuous anterograde amnesia, with additional retrograde amnesia for events of the past four months, occurred as a manifestation of partial status epilepticus: nasopharyngeal electrodes showed frequent bilateral spikes and runs of ictal activity arising independently in both mesiotemporal lobes. Thus ictal amnesia closely resembling TGA can occur as a manifestation of semicontinuous temporal lobe discharges. Similarly, Vuilleumier et $a l^{34}$ have recently described a 41 year old woman with a history of numerous episodes of profound retrograde and apparent retrograde amnesia, occurring since adolescence, which had been regarded as hysterical. Attacks often started on waking, and were preceded by an epigastric aura. An EEG during a severe attack disclosed generalised epileptiform spikes with spike and wave activity at a frequency of $3.5-4 \mathrm{~Hz}$, involving occasional frontotemporal phase reversal. Intravenous clonazepam abolished both the EEG discharges and the amnesia, disclosing unexpectedly clear recall for events occurring during the seizure. Tassinari et $a l^{35}$ and Morrell $^{31}$ describe somewhat similar cases, but these authors emphasise the persistence of the amnesic state at times when no epileptiform activity was apparent on the EEG, comparing it to a "Todd's paralysis" of memory. Palmini et $a l^{9}$ cite the case of a patient with a postictal period of combined anterograde and retrograde amnesia lasting more than a month after a flurry of temporal lobe seizures over a 24 hour period. In conclusion, both brief and prolonged episodes of amnesia, affecting anterograde and/or retrograde memory, can occur as ictal phenomena, but prolonged amnesic states can also occur in the aftermath of ictal activity. It is uncertain, therefore, whether the recurrent episodes of amnesia experienced by our patients represent ictal or postictal phenomena. Ictal EEG studies of patients during 
amnesic episodes might help to clarify these issues. Such studies may also help to disclose the factors which determine whether or not a period of amnesia comes to the patient's notice.

\section{INTERICTAL RETROGRADE MEMORY IMPAIRMENT} IN TEA

Some previous case reports mention "difficulty with memory" occurring between attacks of TEA. ${ }^{1336}$ The occurrence of a pronounced persisting impairment of retrograde memory in association with TEA has been highlighted recently by Kapur, ${ }^{37}$ and by Kopelman et al. ${ }^{8}$ Despite the striking complaints of retrograde memory impairment in our patients, performance on objective tests of both anterograde and retrograde memory was largely within normal limits. The principal exceptions were tests of retrograde memory, on which five patients had a defective score (greater than 2 SD below the controls' mean) on at least one test, although the degree of impairment was modest except in one patient (case 2). Kapur, likewise, found that tests of anterograde memory were normal in his patient with striking complaints of retrograde memory impairment ${ }^{37}$; scores on tests of retrograde memory were depressed. Kopelman's patient ${ }^{8}$ obtained borderline scores on tests of retrograde memory with somewhat poor anterograde memory in relation to his high IQ. Interestingly, a similar combination of impaired retrograde memory with symptoms of poor autobiographical memory but good performance on anterograde memory tests has been reported in a patient with paraneoplastic limbic encephalitis. ${ }^{38}$ Our failure to demonstrate consistent deficits on objective tests of retrograde memory may reflect the patchy nature of the impairment. Several of the patients report lacunes in their autobiographical memory, extending back over a decade or more. Preliminary results of detailed testing of one patient (patient 3), using tailor-made tests of the type used in other similar single case studies, ${ }^{37} 3940$ suggest a profound impoverishment of autobiographical memory for events of the past 30 years. Islands of preserved recall permitted a misleadingly normal score on the AMI in this patient.

What is the explanation for this patchy impairment of remote memory? There are three possibilities: failure to encode episodes into long term memory, failure to consolidate and maintain memories, and failure to retrieve memories which have been successfully acquired. Some factors could potentially impair memory acquisition in such patients including impairment of consciousness in the course of complex partial seizures, anterograde amnesia in the immediate postictal phase, unnoticed episodes of TEA giving rise to anterograde amnesia, or a generalised impairment of anterograde memory. These all seem unlikely explanations for our patients' subjective complaints of retrograde amnesia given that autobiographical memories which predate the clinical onset of their epilepsy - sometimes by a number of years - are affected, and the lack of evidence for impairment of anterograde memory on standard tests. It is clearly difficult to exclude the possibility that patients may have had subclinical seizures for some time before the onset of their TEA attacks, but this seems an unlikely explanation as in one patient (case 3 ) the retrograde amnesia extended back over 30 years.

The second possibility, that an impairment of long term consolidation underlies this persistent retrograde amnesia, merits further consideration. Some patients in our series have told us that their memories for recent personal events seem to be intact initially but may then disappear without trace, suggesting that acquisition is normal but consolidation is impaired. This is in keeping with their normal performance on standard tests of anterograde memory which typically test recall over 30 minutes or so rather than over long periods. Current computational neural network models of long term memory processing, based on human neuropsychological and animal data, ${ }^{41-43}$ suggest that the medial temporal lobe complex plays a critical, but temporally limited, part in the encoding and storage of new episodic memories. Over time a process of long term consolidation or information transfer occurs whereby memories become independent of the hippocampus by the development of direct corticocortico links. Ictal activity in the mesial temporal lobes or involving the temporal neocortex might be capable of disrupting recent memories during this vulnerable stage of consolidation. In this context, it is of interest that TEA often occurs in relation to sleep, as there is accumulating evidence that processes of memory consolidation may be particularly active in sleep. ${ }^{44}{ }^{45}$ The fact that many patients have early morning TEA attacks and show abnormal sleep EEGs suggests that disturbed consolidation during sleep may be a critical factor. In keeping with this hypothesis is the finding of impaired memory at long, but not short, retention intervals in patients with temporal lobe epilepsy. ${ }^{46}$ It is, however, open to question whether disruption of consolidation is an adequate explanation for the impaired recall of very remote episodic and more semantic type memories seen in some of our patients. The occurrence of topographical amnesia for extremely familiar places, impaired recognition of familiar faces, and degradation of established professional abilities points to pathology in the more lateral temporal neocortex in addition to mesial temporal structures. The neural basis of very long term autobiographical and semantic memory remains unclear. Current evidence points to a critical role for the left inferolateral temporal neocortex in the storage of general semantic knowledge ${ }^{46-48}$; the equivalent right sided structure may be specialised for person based knowledge. ${ }^{49}$ It is possible that pathology in these regions which have, for example, a hypoxic basis, could give rise both to epilepsy and to retrograde amnesia. In the absence of more detailed neuroimaging such as volumetric MRI or PET we cannot exclude the possibility of subtle medial or temporal lobe pathology in our cases. Failure of retrieval may be difficult to distinguish from failure of 
storage. Preliminary work with a patient with particularly severe retrograde amnesia (case 3) indicates that his retrograde memory gaps are consistent over time and little improved by cueing: these features argue for a primary failure of consolidation or storage rather than a retrieval deficit.

In conclusion, a persistent impairment of retrograde memory is a common accompaniment of TEA. There is circumstantial evidence that this may be the result of disruption of memory consolidation, related to recurrent ictal activity in mesial temporal structures. Detailed neuropsychological study of individual cases, particularly including analysis of long term forgetting rates, combined with ambulatory EEG recording in patients with ongoing memory disturbance, will be of value in testing this hypothesis.

We thank Dr Peter Harvey, Dr David Dick, Dr Colin Brown, and Dr Iain Wilkinson who referred patients included in this series; Dr Kristen Breen and Dr German Berrios who contribseries; Dr Kristen Breen and Dr German Berrios who contrib-
uted to the assessment of patients in the Cambridge Memory Clinic; Naida Graham and Dr John Greene for providing neuropsychological control data, and Nick Carvill for his techneuropsychological control dat

1 Hughlings-Jackson J. On a particular variety of epilepsy (intellectual aura), one case with symptoms of organic brain (intellectual aura), one case with s.m.
disease. Brain 1989;11:179-207.

2 Penfield W, Mathieson G. Memory: autopsy findings and comments on the role of hippocampus in experiential recall. Arch Neurol 1974;31:145-54.

3 Dugan TM, Nordgren RE, O'Leary P. Transient global amnesia associated with bradycardia and temporal lobe spikes. Cortex 1981;17:633-8.

4 Pritchard PB, Holmstrom VL, Roitzsch JC, et al. Epileptic amnesic attacks: benefit from antiepileptic drugs. Neurology 1985;35:1188-9.

5 Miller JW, Yanagihara T, Petersen RC, et al. Transient global amnesia and epilepsy: electroencephalographic distinction. Arch Neurol 1987;44:629-33.

6 Kapur N. Transient epileptic amnesia-a clinical update and a reformulation. $\mathcal{f}$ Neurol Neurosurg Psychiatry 1993;56:1184-90.

7 Hodges JR. Transient global amnesia. London: WB Saunders, 1991.

8 Kopelman MD, Panayiotopoulos CP, Lewis P. Transient epileptic amnesia differentiated from psychogenic "fugue": neuropsychological, EEG and PET findings. F Neurol Neurosurg Psychiatry 1994;57:1002-4.

9 Palmini AL, Gloor P, Jones-Gotman M. Pure amnestic seizures in temporal lobe epilepsy. Brain 1992;115:749-69.

10 Rowan AJ. Ictal amnesia and fugue states. In: Smith D, Treiman D, Trimble M, eds. Neurobehavioural problems in epilepsy. New York: Raven Press, 1991:357-67.

11 Gallassi R, Morreale A. Transient global amnesia and epilepsy. In: Markowitsch HJ, ed. Transient global amnesia and related disorders. Toronto: Hogrefe and Huber, 1990.

12 Gallassi R, Pazzaglia P, Lorusso S, et al. Neuropsychological findings in epileptic amnesic attacks. Eur Neurol 1986;25: 299-303.

13 Stracciari A, Ciucci G, Bianchedi G, et al. Epileptic transient amnesia. Eur Neurol 1990;30:176-9.

14 Kapur N. Transient epileptic amnesia: a clinically distinct form of neurological memory disorder. In: Markowitsch $\mathrm{H}$,
ed. Transient global amnesia and related disorders. New York: ed. Transient global amnesia and related

15 Hodges JR. Cognitive assessment for clinicians. Oxford: Oxford University Press, 1994.

16 Blume WT, Kaibara M. Atlas of adult encephalography. New York: Raven Press, 1995.

17 Nelson HE, O'Connell A. Dementia: the estimation of levels of premorbid intelligence using the new adult reading test. Cortex 1978;14:234-44.

18 Wechsler DA. Wechsler memory scale-revised. New York: The Psychological Corporation, 1987.
19 Osterrieth P, Rey A. Le test de copie d'une figure complexe. Arch Psychol 1944;30:205-20.

20 Warrington EK. The recognition memory test. Windsor: NFER, 1984

21 Greene JDW, Hodges JR. Identification of famous faces and famous names in early Alzheimer's disease. Brain 1996;19: 111-28.

22 Kopelman MD, Wilson BA, Baddeley AD. The autobiographical memory interview. Bury St Edmunds: Thames Valley Test Company, 1990.

23 Deisenhammer E. Transient global amnesia as an epileptic manifestation. Neurology 1981;225:289-92.

24 Shuping JR. Transient global amnesia due to glioma in the dominant hemisphere. Neurology 1980;30:88-90.

25 Meador KJ, Adams RJ, Flanigin HF. Transient global amnesia and meningioma. Neurology 1985;35:769-71.

26 Fisher CM. Transient global amnesia: precipitating activities and other observations. Arch Neurol 1982;39:605-8.

27 Melo TP. Are brief or recurrent transient global amnesias of epileptic origin? f Neurol Neurosurg Psychiatry 1994.57: $622-5$

28 Squire LR. Memory and the hippocampus: a synthesis from findings with rats, monkeys, and humans. Physiol Rev 1962;99:195-231.

29 Squire LR, Alvarez P. Retrograde amnesia and memory consolidation: a neurobiological perspective. Curr Opin Neurobiol 1995;5:178-83.

30 Bridgman PA, Malamut BL, Sperling MR, et al. Memory during subclinical hippocampal seizures.Neurology 1989; 39:853-6.

31 Morrell F. Memory loss as a Todd's paralysis. Epilepsia 1980;21:185.

32 Lee BI, Lee BC, Hwang YM, et al. Prolonged ictal amnesia with transient focal abnormlaities on magnetic resonance imaging. Epilepsia 1992;33:1042-6.

33 Halgren E, Wilson CL, Stapleton JM. Human medial temporal lobe stimulation disrupts both formation and retrieval of human memories. Brain Cogn 1985;4:287-95.

34 Vuilleumier P, Desplane PA, Regli F. Failure to recall (but not to remember): pure transient amnesia during nonconvulsive status epilepticus. Neurology 1996;46:1036-9.

35 Tassinari CA, Ciarmatori C, Alesi C, et al. Transient global amnesia as a postictal state from recurrent partial seizures. Epilepsia 1991;32:882-5.

36 Gallassi R, Morreale A, Lorusso S, et al. Epilepsy presenting as memory disturbances. Epilepsia 1988;29:624-9.

37 Kapur N. Focal retrograde amnesia: a long term clinical and neuropsychological follow up. Cortex 1989;25:387-402

38 Ahern GL,O'Connor M, Dalmau J, et al. Paraneoplastic temporal lobe epilepsy with testicular neoplasm and atypical amnesia. Neurology 1994;44:1270-4.

39 Hodges JR, McCarthy R. Autobiographical amnesia resulting from bilateral paramedian thalamic infarction. Brain 1993;116:921-40

40 Evans JJ, Breen EK, Antoun N, et al. Focal retrograde amnesia for autobiographical events following cerebral vasculitis: a connectionist account. Neurocase 1996;2:1-12.

41 Alvarez P, Squire LR. Memory consolidation and the medial temporal lobe: a simple network model. Proc Natl Acad Sci USA 1994;91:7041-5.

42 McClelland JL, McNaughton BL, O'Reilly RC. Why are there complementary learning systems in the hippocampus and neocortex: insights from the successes and failures of connectionist models of learning and memory. Psychol Rev 1995;102:419-37.

43 Murre JMJ. Implicit and explicit memory in amnesia: some explanations and predictions by the tracelink model. Memory 1997;5:213-32.

44 Karni A. Dependence on REM sleep of overnight improvement of a perceptual skill. Science 1994;265:679-82.

45 Wilson MA. Reactivation of hippocampal ensemble memories during sleep. Science 1994;265:676-9.

46 Martin RC, Loring DW, Meador KJ, et al. Impaired long-term retention despite normal verbal learning in patients with temporal lobe dysfunction.Neuropsychology 1991;5:3-12.

47 Patterson K, Hodges JR. Disorders of semantic memory. In: Baddeley AD, Wilson BA, Watts FN, eds. Handbook of memory disorders: John Wiley, 1995:167-86.

48 Garrard P, Perry R, Hodges JR. Disorders of semantic memory. $\mathcal{F}$ Neurol Neurosurg Psychiatry 1997;62:431-5

49 Evans JJ, Heggs AJ, Antoun N, et al. Progressive prosopagnosia associated with selective right temporal lobe atrophy: a new syndrome? Brain 1995;118:1-13.

50 Lou HOC. Repeated episodes of transient global amnesia. Acta Neurol Scand 1968;44:612-7. 